\title{
Reproductive Health Care of Adolescent Women
}

\author{
Ronni Hayon, MD, Jessica Dalby, MD, Elizabeth Paddock, MD, Meaghan Combs, MD, \\ and Sarina Schrager, MD, MS
}

Reproductive health care of adolescent women is focused on prevention of disease. Adolescents are at higher risk for pelvic inflammatory disease than adult women; therefore, screening regularly for sexually transmitted infections is important. Immunization for human papillomavirus is the primary means of cervical cancer prevention because new guidelines recommend not initiating Papanicolaou smears until the age of 21. Contraception for adolescents is a challenge, and clinicians should focus on longacting, reversible contraception in this group. The treatment of pelvic pain and menstrual disorders in adolescent women is distinct from adult women and is related to differing prevalence of conditions. Lastly, this article discusses the importance of confidential care when treating adolescent women. ( J Am Board Fam Med 2013;26:460-469.)

Keywords: Adolescence, Contraception, Women's Health

The reproductive health care of adolescent women is often distinct from that of adult women. This article reviews recommendations for preventive gynecologic care for adolescents and treatment of the most common gynecologic complaints seen in primary care.

\section{Preventive Services}

Prevention of unintended pregnancy and sexually transmitted infections are paramount in the adolescent visit. Adolescent patients visit the doctor less often and are less likely to have insurance than any other age group, so preventive services should be addressed during each encounter. ${ }^{1}$

The US Preventive Services Task Force recommends high-intensity behavioral counseling (3 to 9 hours over multiple sessions) to prevent sexually transmitted infections (STIs) for sexually active adolescents (Table 1). High-intensity counseling may reduce the absolute risk of STI transmission by up

This article was externally peer reviewed.

Submitted 17 October 2012; revised 26 December 2012; accepted 14 January 2013.

From the Department of Family Medicine, University of Wisconsin School of Medicine and Public Health, Madison. Funding: none.

Conflict of interest: none declared.

Corresponding author: Ronni Hayon, MD, Department of Family Medicine, University of Wisconsin School of Medicine and Public Health, 1100 Delaplaine Ct., Madison, WI 53715 (E-mail: ronni.hayon@fammed.wisc.edu). to $11 \%$ in this age group. Unfortunately, shorter counseling interventions of $<30$ minutes have not been shown to reduce STI rates. ${ }^{2}$ Given time limitations in the primary care setting, physicians should provide referral to and collaborate with community resources that can offer these interventions, such as school-based programs or community outreach projects. Directing teens to reliable Internet sources may also be beneficial. Whiteley et $\mathrm{al}^{6}$ analyzed websites of sexual health topics directed toward adolescents based on educational content, reliability, interactivity, and navigability. The top 3 websites based on highest cumulative scores were (1) www.plannedparenthood.com/infofor-teens; (2) www.scarleteen.com, and (3) www. avert.org.

All sexually active adolescents should be screened for chlamydia and gonorrhea annually. ${ }^{7}$ In adolescent women, asymptomatic infection increases the risk for pelvic inflammatory disease (PID), leading to further risk of infertility, ectopic pregnancy, and chronic pelvic pain. Screening decreases the incidence of PID by as much as $50 \%{ }^{7}$ Pregnant adolescents should be screened at the first prenatal visit and again in the third trimester. Urine testing may provide a more patient-centered approach if a pelvic examination is not otherwise indicated. If an adolescent requires treatment, she should be tested again in 3 months because of the 
Table 1. Recommended Preventive Services for Adolescents

\begin{tabular}{|c|c|c|c|}
\hline Service & Recommendation & Agency & Grade* \\
\hline \multicolumn{4}{|l|}{ STI counseling } \\
\hline High intensity & $\begin{array}{l}\text { 3-9 Hours of counseling conducted over multiple sessions and in } \\
\text { groups }\end{array}$ & USPSTF & B \\
\hline Brief/short & Single session or intervention lasting $<30$ minutes & USPSTF & I \\
\hline $\begin{array}{l}\text { Cervical cancer screening } \\
\quad \text { (cytology) }\end{array}$ & Do not screen before age 21 & USPSTF & $\mathrm{D}$ \\
\hline HPV testing & Do not use for screening in those younger than 30 & USPSTF & $\mathrm{D}$ \\
\hline HPV vaccination & $\begin{array}{l}\text { Before onset of sexual activity at age } 11 \text { to } 12 \text { years, no earlier } \\
\text { than age } 9 \text { years, in both females and males }\end{array}$ & ACIP & A \\
\hline $\begin{array}{l}\text { Folic acid } \\
\quad \text { supplementation }\end{array}$ & $\begin{array}{l}400-800 \mu \mathrm{g} \text { of folate for all women of reproductive age to } \\
\text { prevent neural tube defects }\end{array}$ & USPSTF & A \\
\hline
\end{tabular}

${ }^{*}$ Grade of recommendations is based on USPSTF definitions: A = high certainty of substantial benefit/offer or provide service; $\mathrm{B}=$ high or moderate certainty of moderate or substantial benefit/offer or provide service; $\mathrm{C}=$ likely only a small benefit for most individuals without signs or symptoms/may provide service to selected patients based on individual circumstances; $\mathrm{D}=$ moderate or high certainty of no benefit or harms outweigh benefits/recommend against service; I = evidence is lacking, of poor quality, or conflicting, and the balance of benefits and harms cannot be determined.

Data taken from U.S. Preventive Services Task Force ${ }^{1-3}$ and the Centers for Disease Control and Prevention. ${ }^{4}$

ACIP, Advisory Committee on Immunization Practices; HPV, human papillomavirus; STI, sexually transmitted infection; USPSTF, U.S. Preventive Services Task Force.

high prevalence of repeat infection. Offering partner treatment is another evidence-based part of prevention. State laws differ with regard to partner treatment, but many do allow for expedited partner therapy, where the provider furnishes the infected patient with a prescription for treatment of her sexual partners without requiring clinical examination of the partners. The legal status of expedited partner therapy varies geographically and can be found at www.cdc.gov/std/ept.

The US Centers for Disease Control and Prevention recommends testing all sexually active individuals for human immunodeficiency virus. ${ }^{8}$ In contrast, the US Preventive Services Task Force recommends screening only high-risk adolescents and pregnant adolescents for human immunodeficiency virus and syphilis (Table 2). ${ }^{9}$ Adolescents at high risk for syphilis include women who engage in high-risk sexual behavior, sex workers, persons who exchange sex for drugs, and those in adult correctional facilities.

Women younger than age 21 should not be screened for cervical cancer or tested for human papillomavirus (HPV), regardless of the age at which they began being sexually active. ${ }^{3,14}$ HPV infection is common in sexually active adolescents. More than $90 \%$ of adolescents will clear this infection within 3 years. Another $50 \%$ of those will go on to become reinfected during that time period. ${ }^{14}$ Despite high rates of infection and reinfection, pro- gression to cervical cancer in adolescents is negligible. Thus, screening for cervical cancer in adolescent women results in net harm, leading to overtreatment and risk of future reproductive problems.

The focus for cervical cancer prevention in adolescents should be on HPV vaccination before the initiation of sexual activity. The HPV vaccine is highly effective, with studies reporting $98 \%$ effec-

Table 2. Summary of U.S. Preventive Services Task Force (USPSTF) Screening Recommendations for Sexually Transmitted Infections (STIs) in Adolescent Women

\begin{tabular}{lccc}
\hline STI Screening & Low risk & High risk & Pregnant \\
\hline Chlamydia & A & A & B $^{*}$ \\
Gonorrhea & B & B & B $^{*}$ \\
HIV & C & A & A \\
Herpes & D & D & D \\
Syphilis & D & A & A \\
Hepatitis B & D & D & A \\
HPV & D & D & D \\
\hline
\end{tabular}

Grade of recommendations are based on USPSTF definitions: A = high certainty of substantial benefit/offer or provide service; $\mathrm{B}=$ high or moderate certainty of moderate or substantial benefit/offer or provide service; $\mathrm{C}=$ likely only a small benefit for most individuals without signs or symptoms/may provide service to selected patients based on individual circumstances; $\mathrm{D}=$ moderate or high certainty of no benefit or harms outweigh benefits/recommend against service.

* Screen during the first and third trimesters.

Data from Refs. 3, 7, and 9-13. 
tiveness in preventing advanced cervical dysplasia and $99 \%$ effectiveness in preventing genital warts. ${ }^{5}$

\section{Contraception}

The rate of adolescent births in the United States has been declining over the past decade despite the fact that $70 \%$ of adolescent women will have had intercourse by their 19th birthday. ${ }^{15}$ In 2010, the number of live births among 15- to 19-year-olds was 367,753 , which represents the lowest rate in this country since $1946 .{ }^{16}$ Unintended pregnancy remains a serious public health issue, and the United States lags behind other countries in prevention. Of sexually active adolescent women, 90\% will get pregnant over a 1 -year period if they are sexually active and do not use contraception. ${ }^{15}$

The condom is the most commonly used contraceptive among adolescents in the United States, followed by withdrawal and oral contraceptive pills (OCPs). ${ }^{17}$ One recent survey found that $80 \%$ of males and $70 \%$ of females aged 14 to 17 reported condom use during their last episode of vaginal intercourse. ${ }^{18}$ Unfortunately, typical failure rates for the condom can be as high as $17 \%$ in the first year. ${ }^{19}$ Young people benefit from hands-on experience with condoms as well as role playing to improve their skills in negotiating condom use with their partners, yet fewer than $20 \%$ of clinicians actually teach correct condom use during visits with adolescents. ${ }^{19}$

The failure rate for typical use of OCPs reaches $8 \%$, and young women have the highest rates of failure. ${ }^{20}$ Clinicians should offer long-acting reversible contraceptives (LARCs) such as intrauterine devices (IUDs), contraceptive implants, and contraceptive injections (Depot medroxyprogesterone acetate [DMPA]) and work to remove barriers that adolescents face when trying to access these forms of contraception.

The IUD is a safe LARC that does not increase risk of PID or STIs. In fact, some studies have shown that the levonorgestrel (LNG) IUD actually reduces a woman's risk of PID, likely because the progesterone in the device thickens cervical mucus and thins the endometrial lining. ${ }^{21}$ Adolescents should be tested for chlamydia and gonorrhea before insertion, but one may perform these tests at the time of insertion to improve access to contraception. Prophylactic antibiotics are not necessary at the time of insertion. Patients with positive culture results should be treated with appropriate antibiotics. The IUD does not need to be removed. ${ }^{22}$
Nulliparity is not a contraindication to the IUD. The World Health Organization Medical Eligibility Criteria list IUDs as category 2, for which advantages generally outweigh theoretical or proven risks for women from menarche until 20 years of age. While insertion can sometimes be challenging, once inserted, the IUD seems to be acceptable to adolescents. One small, randomized study demonstrated 6-month continuation rates among adolescents to be $76 \%$ for the LNG IUD (Mirena; Bayer HealthCare Pharmaceuticals, Inc., Wayne, NJ) and $45 \%$ for the copper IUD (ParaGard; TEVA Women's Health, Inc., Sellersville, PA). ${ }^{23}$

DMPA (Depo-Provera; Pfizer, New York, NY) is another LARC that is often underprescribed to adolescents because of concerns about bone mineral density (BMD). There is a significant decrease in BMD in adolescents who use DMPA compared with those who do not. However, the losses in BMD sustained while taking DMPA are reversible, with a return to baseline BMD within 1 to 2 years of discontinuation. ${ }^{24}$ Despite this evidence, in 2004, the US Food and Drug Administration placed a black box warning on DMPA, recommending that DMPA be used longer than 2 years "only if other birth control methods are inadequate." 25 The World Health Organization, the American College of Obstetricians and Gynecologists, and the Society for Adolescent Medicine all have issued position statements acknowledging that the benefits of DMPA often outweigh the risks, especially in an adolescent population. All 3 entities advise against limiting use to 2 years based solely on concerns about BMD. ${ }^{26-28}$

The contraceptive implant (Implanon [Schering-Plough Corp], Nexplanon [Merck]) is a LARC consisting of a single rod that contains etonogestrel and is implanted subdermally. It is approved for up to 3 years of continuous use. It is an effective method for adolescents because it is not user-dependent and is confidential. The benefits of the implant include an annual failure rate of $<1 \%$ as well as a rapid return to fertility after discontinuation. Ovulation occurs in $94 \%$ of women within 3 to 6 months of removal. ${ }^{29}$

Both the transdermal patch and the vaginal ring are options for the adolescent patient, although they are not as effective as a LARC. A recent prospective cohort study with 9,256 participants demonstrated that there were significantly higher rates of unintended pregnancy among women using the pill, 
patch, or ring compared with women using an IUD, contraceptive implant, or DMPA. Failure rates for women using non-LARC methods had a risk of method failure that was almost 20 times that of women using LARCs. Women younger than 21 years old who were using the pill, patch, or ring had twice the risk of unintended pregnancy compared with older women using the same method. ${ }^{30}$

Options for emergency contraception (EC) include the copper IUD, levonorgestrel formulations (Plan B, Next Choice), and ulipristal acetate (Ella), which is a progesterone receptor modulator. All methods containing LNG are available without a prescription to individuals 17 years of age and older, but a prescription is required for patients 16 years old or younger. Ulipristal acetate is more effective than LNG EC, especially 72 to 120 hours after unprotected sex or method failure. It is available by prescription only. Rates of pregnancy and STIs are not significantly increased by advance provision of EC by clinicians or pharmacy access to EC. ${ }^{31}$ Clinical examinations and pregnancy testing are not necessary before provision of EC.

Given the exceptionally high rates of efficacy of LARC methods, they should be considered firstline contraceptive methods for all adolescents. Table 3 provides tips on how to improve access to contraception for adolescents.

\section{Table 3. Ways to Improve Adolescents' Access to}

\section{Contraception}

- Urge adolescents to use LARC methods such as the IUD, contraceptive implant, or DMPA.

- Provide COCs, DMPA, and condoms without requiring a complete gynecological exam. Pap smears are not recommended until age 21 .

- Develop clear office policies on confidentiality for adolescent patients, and share these policies with patients, parents, and staff.

- Provide free condoms to adolescents.

- Use advance provision of EC for adolescents (with refills).

- When prescribing OCPs, prescribe at least 3 months' worth of pills, and consider prescribing an entire year's supply.

- Include troubleshooting with adolescents when discussing contraception choices (eg, "How will you remember to take your pill every day? Can you set a reminder on your cell phone?")

- Provide hands-on teaching with condoms and facilitate role-playing to help adolescents improve negotiating skills.

COC, combined oral contraceptives; DMPA, contraceptive injection; EC, emergency contraception; IUD, intrauterine device; LARC, long-acting reversible contraceptive; OCP, oral contraceptive pill.

\section{Pelvic Pain}

Pelvic pain is a common presenting symptom of adolescent women, with a prevalence of $14 \%$ to $16 \%$ in the general population. ${ }^{32} \mathrm{~A}$ basic framework for evaluating pelvic pain is to differentiate acute ( $<3$ months' duration) versus chronic pain and gynecologic versus nongynecologic causes. Here we focus on gynecologic causes of pelvic pain in the adolescent.

\section{Acute Pelvic Pain}

Acute pelvic pain can be difficult to diagnose. ${ }^{33}$ It is most important to exclude life-threatening and fertility-threatening conditions. There is no good data on the rates of acute pelvic pain in adolescent women. The differential diagnosis is similar to that in adult women; however, anatomic anomalies that prevent menstruation (Müllerian duct abnormalities, imperforate hymen) must be included. Rates of PID are much higher in the adolescent population. $^{33}$

Life-threatening conditions include ectopic pregnancy, appendicitis, and ruptured ovarian cyst. Fertility-threatening conditions include PID and ovarian torsion. Of these conditions, PID, appendicitis, and ruptured ovarian cyst are the most common. ${ }^{34}$ If a woman presents with sudden onset of acute abdominal or pelvic pain, ovarian torsion must be considered, and referral for urgent ultrasound should be pursued.

\section{Chronic Pelvic Pain}

The American College of Obstetricians and Gynecologists defines chronic pelvic pain as noncyclic pain of 3 months' duration or cyclic pain of 6 months' duration that interferes with normal activity. ${ }^{35}$ The most common diagnoses in adolescents are dysmenorrhea, endometriosis, ovarian cysts, musculoskeletal causes, PID, pelvic adhesions, and irritable bowel syndrome. ${ }^{36} \mathrm{Up}$ to $50 \%$ of women with chronic pelvic pain have a history of physical or sexual abuse. ${ }^{35}$

\section{Dysmenorrhea}

Dysmenorrhea is the most common gynecologic complaint among adolescent females. It is characterized by severe cramping pain in the lower abdomen just before and during menses. The pain is often associated with nausea, vomiting, and headache. ${ }^{37}$ Dysmenorrhea is seen more frequently in 
mid- to late adolescence after menstrual cycles become ovulatory. Among young women it is the most common cause of recurrent, short-term absenteeism from school or work. ${ }^{37}$ The prevalence of dysmenorrhea in adolescents has been reported at $40 \%$ to $90 \% .^{37}$

The majority of adolescents with dysmenorrhea have a normal ovulatory cycle and no pelvic pathology. This is classified as primary, or functional, dysmenorrhea. ${ }^{38}$ In primary dysmenorrhea, the production of prostaglandins following progesterone withdrawal as part of the normal menstrual cycle leads to an inflammatory response that causes cramping (myometrial contractions), nausea, vomiting, bloating, and headaches. ${ }^{37-39}$

Dysmenorrhea in the setting of pelvic abnormalities is termed secondary dysmenorrbea and is seen in approximately $10 \%$ of adolescents with dysmenorrhea, usually presenting during later adolescence. ${ }^{39}$ Common causes of secondary dysmenorrhea are endometriosis, congenital malformations (eg, imperforate hymen), cervical stenosis, and pelvic infections. $^{38}$

Management of dysmenorrhea starts with nonsteroidal anti-inflammatory drugs (NSAIDs) and OCPs. NSAIDs work by reducing prostaglandin production; there is no clear evidence that one NSAID works better than another. ${ }^{39}$ OCPs improve dysmenorrhea by thinning the endometrial lining, leading to decreased prostaglandin production and inhibiting ovulation. Some adolescents will continue to have symptoms when having a withdrawal bleed and will benefit from continuous cycling. ${ }^{38,39}$ Nonpharmacologic therapies including a low-fat vegetarian diet, omega 3 fatty acid supplementation, exercise, and topical heat may provide symptomatic relief as well. ${ }^{39}$

One study demonstrated a two-thirds reduction in dysmenorrhea symptoms with DMPA. ${ }^{40}$ There is limited data from adolescents on the use of the LNG IUD (Mirena). Its use to improve menstrual pain in women aged 25 to 47 is well established. ${ }^{41}$ There is no data on the other combined contraceptives for dysmenorrhea.

One approach to managing dysmenorrhea is to start scheduled NSAIDs 1 to 2 days before the onset of menses and to continue taking scheduled doses for the next few days. If a woman is unable to predict when her period is to begin, she should start NSAIDs at the onset of symptoms or bleeding. If after 3 cycles the patient continues to have pain, an
Table 4. Common Presenting Symptoms of Adolescent

\section{Endometriosis}

Acyclic or cyclic pelvic pain, often with radiation to back or lower extremities

Dysmenorrhea

Abnormal uterine bleeding and associated cramping

Deep dyspareunia

Gastrointestinal symptoms- abdominal pain, nausea, diarrhea, constipation

Symptoms are usually severe enough that the adolescent has missed school or other activities.

Many of these patients have previously presented to an emergency department or another physician because of the pain.

OCP should be tried. If after 3 cycles on the OCP the adolescent's pain has not improved, then secondary dysmenorrhea should be suspected.

\section{Endometriosis}

Endometriosis frequently presents with dysmenorrhea, dyspareunia, or pelvic and abdominal pain (Table 4). Endometriosis pain is thought to be the result of deposits of endometrial tissue outside of the uterine cavity. ${ }^{45}$ A definitive diagnosis of endometriosis is made by histopathology of lesions removed during surgery. Imaging typically will be negative unless an endometrioma (endometrial lesions that have grown to form a cystic structure) is present. Endometriomas are less common in women younger than 20 years old. ${ }^{39}$ It is estimated that $6 \%$ to $10 \%$ of women of reproductive age have endometriosis. ${ }^{45}$ In adolescents with pelvic pain that is not controlled with medications, the incidence of endometriosis increases to $60 \%$ to $70 \%$ at the time of laparoscopy. ${ }^{45}$ Risk factors for developing endometriosis are early menarche $(<11$ years old), short cycles ( $<27$ days), and heavy, long menses. $^{45}$

A presumptive diagnosis of endometriosis can be made based on a patient's history and physical examination. In adolescents, preservation of future fertility is important when choosing treatment options. Initial treatment includes OCPs and NSAIDS. OCPs can be taken continuously to prevent dysmenorrhea. Other considerations can be DMPA or the LNG IUD. ${ }^{45}$

If pain is not adequately controlled following medical management, referral for possible laparoscopy is appropriate. ${ }^{36,38,45}$ Several studies have shown that endometriosis is as common in adoles- 
Table 5. Potential Sequelae of Pelvic Inflammatory Disease

Chronic pelvic pain

Adhesions

Tubal occlusion

Increased risk of ectopic pregnancy

Infertility

cents with chronic pelvic pain as in the general population, and laparoscopy with removal of endometrial lesions can be beneficial in managing pain. ${ }^{35}$

\section{Ovarian Cyst Disease}

Adolescents are more prone to ovarian cysts because the time period following initiation of menses can be associated with dysfunctional ovulation and subsequent cyst formation. Ovarian cysts can present with cyclical pain, irregular menses, or dysmenorrhea. Once STIs and pregnancy are excluded, transvaginal ultrasound images should be obtained. $^{36}$

In adolescent women, adnexal masses or cysts revealed by ultrasound should be followed conservatively with serial ultrasounds. The majority of functional cysts will regress in 2 to 3 cycles. If a cyst has not regressed or resolved after 4 to 5 cycles, then referral for laparoscopy and surgical diagnosis is appropriate. ${ }^{36}$ The most common cause of solid ovarian tumor in adolescents is a mature teratoma. ${ }^{38}$ A recent Cochrane review found that OCPs do not improve the rate of regression of ovarian cysts and thus should not be used for this purpose. $^{46}$

\section{Pelvic Adhesions}

Pelvic adhesions may occur following abdominal or pelvic surgery, infection (acute or chronic), or en- dometriosis. Adhesions are believed to be a cause of chronic pelvic pain, but there is mixed evidence to support this. In observational studies, up to $89 \%$ of adolescent women have improvement in symptoms following lysis of adhesions. ${ }^{36}$ The only clinical trial has shown that only women with dense adhesions to bowel have a decrease in pain following surgery. ${ }^{35}$

\section{Pelvic Inflammatory Disease}

Adolescents are at higher risk of PID than adult women for multiple reasons. Adolescent women often practice higher-risk behaviors (less use of condoms, use of alcohol/drugs in conjunction with sexual activity); they have lower levels of protective antibodies to STIs, and there is a higher prevalence of gonorrhea and chlamydia among the adolescent population. ${ }^{38}$ Women between 15 to 24 years old make up about $25 \%$ of the sexually active population, but they account for nearly half of all new STI diagnosis each year. ${ }^{15}$ The incidence of PID doubles in women who have intercourse before age $16 .{ }^{38}$

PID can have long-term consequences (Table 5), so it is important to treat it appropriately. Of all women who have acute PID, $18 \%$ to $35 \%$ will go on to develop chronic pelvic pain. ${ }^{46}$ Any adolescent who presents with acute or chronic pelvic pain along with uterine, adnexal, or cervical motion tenderness should be evaluated and treated presumptively for PID. ${ }^{33}$ Table 6 provides some guidelines for treating pelvic pain in adolescents.

\section{Menstrual Cycle Disorders}

The most common menstrual cycle disorders in adolescents are primary amenorrhea, anovulatory bleeding, and menorrhagia and affect approximately $75 \%$ of girls by late adolescence. ${ }^{43} \mathrm{~A}$ thorough history is one of the most important

Table 6. Practice Recommendations for Treating Pelvic Pain in Adolescents

Transvaginal ultrasound is the imaging modality of choice in the initial evaluation of pelvic pain. 
aspects of the evaluation of abnormal uterine bleeding in an adolescent woman. Undiagnosed pregnancy poses serious health risks in an ado- lescent presenting with abnormal uterine bleeding; thus a pregnancy test should always be included in the evaluation. ${ }^{43}$

Table 7. Causes of Primary Amenorrhea

\begin{tabular}{|c|c|c|c|}
\hline Causes & Incidence & Clinical Findings & Treatment \\
\hline \multicolumn{4}{|l|}{$\begin{array}{l}\text { Structural/anatomical } \\
\text { abnormalities }\end{array}$} \\
\hline \multirow[t]{3}{*}{ Mullerian agenesis } & $1 / 4,000$ to $1 / 10,000$ & $\begin{array}{l}\text { Amenorrhea with normal external } \\
\text { genitalia, but absent upper } \\
\text { genital tract }\end{array}$ & Support, counseling \\
\hline & & $\begin{array}{l}\text { Rare; increasingly worsening } \\
\text { cyclical pelvic pain (if } \\
\text { rudimentary uterus present) }\end{array}$ & $\begin{array}{l}\text { Surgical removal of } \\
\text { remnant }\end{array}$ \\
\hline & & Inability to have intercourse & $\begin{array}{l}\text { Surgical creation of } \\
\text { neovagina }\end{array}$ \\
\hline $\begin{array}{l}\text { Androgen } \\
\text { insensitivity }\end{array}$ & $1 / 60,000$ & $\begin{array}{l}\text { Amenorrhea with normal external } \\
\text { genitalia, vaginal "dimple," } \\
\text { absent uterus and cervix, testes } \\
\text { in abdominal cavity or inguinal } \\
\text { canal }\end{array}$ & $\begin{array}{l}\text { Support, counseling } \\
\text { Possible surgical } \\
\text { creation of neovagina } \\
\text { Removal of testes } \\
\text { (age 20) }\end{array}$ \\
\hline Imperforate hymen & $1 / 1000$ & $\begin{array}{l}\text { Amenorrhea with cyclic } \\
\text { abdominal pain, hematocolpos, } \\
\text { hematometra, hemoperitoneum }\end{array}$ & $\begin{array}{l}\text { Surgical removal of the } \\
\text { hymenal tissue }\end{array}$ \\
\hline & & Bluish and bulging hymen & \\
\hline \multicolumn{4}{|l|}{$\begin{array}{l}\text { Primary } \\
\text { hypogonadism }\end{array}$} \\
\hline Gonadal dysgenesis & Varies depending on etiology & Varies depending on etiology & $\begin{array}{l}\text { Varies depending on } \\
\text { etiology }\end{array}$ \\
\hline $\begin{array}{l}\text { Premature ovarian } \\
\text { failure }\end{array}$ & $\begin{array}{l}10 \% \text { to } 28 \% \text { of women with } \\
\text { primary amenorrhea }\end{array}$ & $\begin{array}{l}\text { History of ovarian injury } \\
\text { (surgical, chemotherapy, } \\
\text { radiation therapy), autoimmune } \\
\text { disease, or chromosomal } \\
\text { disorder }\end{array}$ & $\begin{array}{l}\text { Support, counseling, risk } \\
\text { reduction for } \\
\text { osteoporosis and } \\
\text { cardiovascular disease } \\
\text { Estrogen replacement } \\
\text { Fertility assistance }\end{array}$ \\
\hline \multicolumn{4}{|l|}{ HPA axis dysfunction } \\
\hline \multirow[t]{2}{*}{$\begin{array}{l}\text { Functional } \\
\text { hypothalamic } \\
\text { amenorrhea }\end{array}$} & $\begin{array}{l}\text { Most common form of amenorrhea } \\
\text { in adolescence }\end{array}$ & $\begin{array}{l}\text { Low levels of estrogen, LH, and } \\
\text { FSH }\end{array}$ & $\begin{array}{l}\text { Correct underlying } \\
\text { cause of hypothalamic } \\
\text { dysfunction }\end{array}$ \\
\hline & & $\begin{array}{l}\text { Anorexia nervosa, excessive } \\
\text { exercise, excessive stress }\end{array}$ & $\begin{array}{l}\text { Promote bone mineral } \\
\text { density } \\
\text { OCPs }\end{array}$ \\
\hline Kallman syndrome & Rare genetic disorder & $\begin{array}{l}\text { Amenorrhea, lack of pubertal } \\
\text { development, anosmia }\end{array}$ & $\begin{array}{l}\text { Hormone replacement } \\
\text { therapy, BMD } \\
\text { monitoring }\end{array}$ \\
\hline \multirow[t]{2}{*}{ Hyperprolactinemia } & $\begin{array}{l}\text { Cause of } 1 \% \text { of primary and } 15 \% \text { of } \\
\text { secondary amenorrhea }\end{array}$ & $\begin{array}{l}\text { Elevated prolactin level, } \\
\text { hypothyroidism, antipsychotic } \\
\text { medication use }\end{array}$ & $\begin{array}{l}\text { MRI of pituitary fossa } \\
\text { for refractory or } \\
\text { excessive prolactin } \\
\text { level }(>100 \mathrm{ng} / \mathrm{mL})\end{array}$ \\
\hline & & Galactorrhea is rare & Bromocriptine \\
\hline \multicolumn{4}{|l|}{ Multifactorial } \\
\hline PCOS & & $\begin{array}{l}\text { Oligomenorrhea, hirsutism, acne, } \\
\text { obesity, insulin resistance }\end{array}$ & $\begin{array}{l}\text { Weight loss, exercise, } \\
\text { OCPs for menstrual } \\
\text { regulation, insulin } \\
\text { sensitizing medication } \\
\text { (eg, metformin) to } \\
\text { treat hyperinsulinemia }\end{array}$ \\
\hline
\end{tabular}

Data from Refs. 42-44.

BMD, bone mineral density; FSH, follicle-stimulating hormone; HPA, hypothalamic-pituitary axis; LH, luteinizing hormone; MRI, magnetic resonance imaging; OCP, oral contraceptive pill; PCOS, polycystic ovarian syndrome. 
Primary amenorrhea is defined as a lack of menstruation in a 14-year-old girl with no secondary sexual characteristics or in a 16-year-old girl with secondary sexual characteristics. ${ }^{44}$ The most common causes of amenorrhea in adolescents are hypothalamic amenorrhea, polycystic ovarian syndrome, hyperprolactinemia, and ovarian failure. ${ }^{47}$ Other etiologies to consider include adrenal and ovarian tumors, drug effects, congenital adrenal hyperplasia, physical or emotional stress, anorexia nervosa, and the female athlete triad. ${ }^{43,48}$ Treatment depends on the underlying etiology $^{43}$ (Table 7).

Menorrhagia (heavy menstrual bleeding) is often a presenting symptom of a coagulopathy. Up to $20 \%$ of adolescents admitted to a hospital with severe menorrhagia have an underlying clotting disorder. ${ }^{49}$ Von Willebrand disease is the most common bleeding disorder in the general population, with a prevalence of $1 \%$ to $2 \%$. Among adolescents with menorrhagia, Von Willebrand disease occurs in $5 \%$ to $35 \%$ of patients. ${ }^{50}$ Platelet dysfunction, clotting factor deficiencies, and thrombocytopenia are also common.

Initial laboratory evaluation of menorrhagia includes a pregnancy test, a complete blood cell count, partial thromboplastin time, prothrombin time, and a fibrinogen level. If the history of bleeding is strong, testing for Von Willebrand disease with a Von Willebrand factor protein and the ristocetin cofactor should also be considered. ${ }^{51}$

Treatment of menorrhagia is based on the amount of flow, degree of patient anemia, and shared decision making between the patient and her parents/guardians regarding treatment options. ${ }^{52}$ If the patient has light to normal flow and no sign of anemia, reassurance should be offered. For patients with moderate bleeding, NSAIDs have been shown to decrease bleeding by as much as $47 \% .{ }^{43}$ Low-dose combined oral contraceptives or cyclic progestins may also be helpful. ${ }^{53}$ The LNG IUD is also an option and offers the added benefit of a LARC. Use of an LNG IUD led to a $94 \%$ improvement in heavy menstrual bleeding and a $92 \%$ improvement in dysmenorrhea in one study of 48 patients age 13 to $18 .^{54}$

Tranexamic acid is an antifibrinolytic agent that may reduce bleeding from menorrhagia by $40 \%$ to $50 \%{ }^{55}$ Tranexamic acid is not associated with a proven, statistically significant increase in thromboembolic disease. ${ }^{55}$ The most common side effects are nausea and vomiting.

Anovulatory bleeding with irregular cycles is quite common in adolescents, with up to $50 \%$ of cycles during the first year of menarche being anovulatory. ${ }^{56}$ Many teens experience irregular menses for 2 to 3 years after menarche because anovulatory cycles and immature hypothalamic-pituitary axis. $^{52,55}$ In these young women, estrogen does not stimulate a surge of luteinizing hormone. Up to $10 \%$ to $20 \%$ of cycles remain anovulatory for 5 years after menarche. ${ }^{39}$ Reassurance is appropriate in these situations, though OCPs are frequently used to regulate cycles.

\section{Confidentiality in Adolescent Care}

The assurance of confidentiality is important to the reproductive health care of adolescent women. In one large study of more than 1,500 women younger than age 18 who were attending a family planning clinic, $20 \%$ said they would use no contraception or withdrawal if parental notification was mandated, and $46 \%$ would use an over-the-counter method of contraception. ${ }^{56}$ In this same study, however, more than half of the participants reported that a parent or guardian knew they were accessing the clinic.

It is a challenge for the clinician to assure the adolescent patient of her confidentiality while at the same time encouraging her to involve responsible adults in her decision-making process. $^{57}$ There is considerable variation in state laws regarding access to contraception. ${ }^{58}$ All states approve screening and treatment of minors for STIs with-

Table 8. Clinician Resources on State-Specific Laws About Adolescent Reproductive Health Care

\begin{tabular}{ll}
\hline Website & Resources \\
www.guttmacher.org & $\begin{array}{c}\text { Specific information on state policies on minor consent laws, access to reproductive health services, } \\
\text { and parental rights } \\
\text { Physicians for reproductive health and choice has developed cards on minors' access to reproductive } \\
\text { health services for 13 states } \\
\text { Thww.prch.org }\end{array}$ \\
www.cahl.org & Thenter for adolescent health and the law has for purchase a summary of state minor consent laws
\end{tabular}


out parental consent. ${ }^{58}$ There are several resources for clinicians that specifically address each state's individual laws (Table 8).

\section{References}

1. Ziv A, Boulet JR, Slap G. Utilization of physician offices by adolescents in the United States. Pediatrics 1999;104(1 Pt 1):35-42.

2. U.S. Preventive Services Task Force. Behavioral counseling to prevent sexually transmitted infections: U.S. Preventive Services Task Force Recommendation Statement. Ann Intern Med 2008;149: 491-6, W95.

3. U.S. Preventive Services Task Force. Screening for cervical cancer. June 2012. Available from: http:// www.uspreventiveservicestaskforce.org/uspstf/ uspscerv.htm. Accessed September 15, 2012.

4. U.S. Preventive Services Task Force. Folic acid to prevent neural tube defects. May 2009. Available from: http://www.uspreventiveservicestaskforce.org/ uspstf/uspsnrfol.htm. Accessed September 15, 2012.

5. Centers for Disease Control and Prevention (CDC). FDA licensure of bivalent human papillomavirus vaccine (HPV2, Cervarix) for use in females and updated HPV vaccination recommendations from the Advisory Committee on Immunization Practices (ACIP). MMWR Morb Mortal Wkly Rep 2010;59: 626-32.

6. Whiteley LB, Mello J, Hunt O, Brown LK. A review of sexual health web sites for adolescents. Clin Pediatr 2012;51:209-13.

7. US Preventive Services Task Force. Screening for chlamydial infection: U.S. Preventive Services Task Force recommendation statement. Ann Intern Med 2007;147:128-34.

8. Centers for Disease Control and Prevention (CDC). Revised recommendations for HIV testing of adults, adolescents, and pregnant women in health-care settings. MMWR 2006;55(RR-14):1-17.

9. U.S. Preventive Services Task Force. Screening for HIV. April 2013. Available from: http://www. uspreventiveservicestaskforce.org/uspstf/uspshivi.htm. Accessed September 15, 2012.

10. U.S. Preventive Services Task Force. Screening for gonorrhea. April 2013. Available from: http:// www.uspreventiveservicestaskforce.org/uspstf/ uspsgono.htm. Accessed May 13, 2013.

11. U.S. Preventive Services Task Force. Screening for genital herpes. March 2005. Available from: http:// www.uspreventiveservicestaskforce.org/uspstf/ uspsherp.htm, accessed 9/15/12.

12. Screening for Syphilis Infection, Topic Page. July 2004. U.S. Preventive Services Task Force. http:// www.uspreventiveservicestaskforce.org/uspstf/ uspssyph.htm. Accessed September 15, 2012.

13. U.S. Preventive Services Task Force. Screening for hepatitis B infection in nonpregnant adolescents and adults. March 2013. Available from: http://www. uspreventiveservicestaskforce.org/uspstf/uspshepb.htm. Accessed May 13, 2013.

14. Moscicki AB, Cox JT. Practice improvement in cervical screening and management (PICSM): symposium on management of cervical abnormalities in adolescents and young women. J Low Genit Tract Dis 2010;14:73-80.

15. Guttmacher Institute. Facts on American teen's sexual and reproductive health. February 2013. Available from: http://www.guttmacher.org/pubs/FBATSRH.pdf. Accessed July 26, 2012.

16. Hamilton BE, Ventura SJ. Birth rates for U.S. teenagers reach historic lows for all age and ethnic groups. NCHS Data Brief Number 89. April 2012. Available from: http://www.cdc.gov/nchs/data/databriefs/ db89.pdf. Accessed July 26, 2012.

17. Martinez G, Copen CE, Abma JC. Teenagers in the United States: sexual activity, contraceptive use, and childbearing, 2006-2010 national survey of family growth. Vital Health Stat 23 2011;(31):1-35. Available from: http://www.cdc.gov/nchs/data/series/sr_23/ sr23_031.pdf. Accessed July 26, 2012.

18. Reece M, Herbenick D, Schick V, Sanders SA, Dodge B, Fortenberry JD. Condom use rates in a national probability sample of males and females aged 14 to 94 in the United States. J Sex Med 2010;7(Suppl 5):266-76.

19. Williams RL, Fortenberry JD. Update on adolescent condom use. Curr Opin Obstet Gynecol 2011;23: 350-4.

20. French RS, Cowan FM. Contraception for adolescents. Best Pract Res Clin Obstet Gynaecol 2009;23: 233-47.

21. Toivonen J, Luukkainen T, Allonen H. Protective effect of intrauterine release of levonorgestrel on pelvic infection: three years' comparative experience of levonorgestrel- and copper-releasing intrauterine devices. Obstet Gynecol 1991;77:261-4.

22. American College of Obstetricians and Gynecologists Committee on Gynecologic Practice. ACOG Committee Opinion No 392, December 2007. Intrauterine device and adolescents. Obstet Gynecol 2007;110:1493-5.

23. Godfrey EM, Memmel LM, Neustadt A, et al. Intrauterine contraception for adolescents aged 14-18 years: a multicenter randomized pilot study of levonorgestrel-releasing intrauterine system compared to the Copper $\mathrm{T}$ 380A. Contraception 2010;81:123-7.

24. Isley MM, Kaunitz AM. Update on hormonal contraception and bone density. Rev Endocr Metab Disord 2011;12:93-106.

25. U.S. Food and Drug Administration. Safety: DepoProvera (medroxyprogesterone acetate injectable suspension). June 19, 2009. Available from: http:// www.fda.gov/Safety/MedWatch/SafetyInformation/ SafetyAlertsforHumanMedicalProducts/ucm 154784. htm. Accessed July 26, 2012. 
26. World Health Organization. WHO statement on hormonal contraception and bone health. Wkly Epiodemiol Rec 2005;80:302-4.

27. American College of Obstetricians and Gynecologists Committee on Gynecologic Practice. ACOG Committee Opinion No. 415: Depot medroxyprogesterone acetate and bone effects. Obstet Gynecol 2008;112:727-30.

28. Cromer BA, Scholes D, Berenson A, Cundy T, Clark MK, Kaunitz AM; Society for Adolescent Medicine. Depot medroxyprogesterone acetate and bone mineral density in adolescents-the Black Box Warning: a Position Paper of the Society for Adolescent Medicine. J Adolesc Health 2006;39:296-301.

29. Tolaymat LL, Kaunitz AM. Long-acting contraceptives in adolescents. Curr Opin Obstet Gynecol 2007;19:453-60.

30. Winner B, Peipert JF, Zhao Q, et al. Effectiveness of long-acting reversible contraception. N Engl J Med 2012;366:1998-2007.

31. Raine T, Harper CC, Rocca CH, et al. Direct access to emergency contraception through pharmacies and effect on unintended pregnancy and STIs: a randomized controlled trial. JAMA 2005;293:54-62.

32. Hulka JF, Peterson HB, Phillips JM, et al. Operative laparoscopy. American Association of Gynecologic Laparoscopists 1991 membership survey. J Reprod Med 1993;38:569.

33. Kruszka P, Kruszka S. Evaluation of acute pelvic pain in women. Am Fam Physician 2010;82:141-7.

34. Morino M, Pellegrino L, Castagna E, Farinella E, Mao P. Acute nonspecific abdominal pain: a randomized, controlled trial comparing early laparoscopy versus clinical observation. Ann Surg 2006;244: 881-8.

35. ACOG Committee on Practice Bulletins-Gynecology. ACOG Practice Bulletin No. 51. Chronic pelvic pain. Obstet Gynecol 2004;103:589-605.

36. Sanfilippo JS, Black A. Adolescent pelvic pain. Best Pract Res Clin Obstet Gynaecol 2003;17:93-101.

37. Klein JR, Litt IF. Epidemiology of adolescent dysmenorrhea. Pediatrics 1981;68:661-4.

38. Song A, Advincula A. Mini-review: adolescent chronic pelvic pain. J Pediatr Adolesc Gynecol 2005; 18:371-7.

39. Harel Z. Dysmenorrhea in adolescents and young adults: etiology and management. J Pediatr Adolesc Gynecol 2006;19:363-71.

40. Harel Z, Biro FM, Kollar LM. Depo-Provera in adolescents: effects of early second injection on prior oral contraception. J Adolesc Health 1995;16: 379-84.

41. Baldaszti E, Wimmer-Puchinger B, Loschke K. Acceptability of the long-term contraceptive levonorgestrel-releasing intrauterine system (Mirena $\left.{ }^{\circledR}\right)$ : a 3-year follow-up study. Contraception 2003;67: 87-91.

42. Sanfilippo J, Lara-Torre E. Adolescent gynecology. Obset Gynecol 2009;113:935-47.
43. Slap G. Menstrual disorders in adolescence. Best Pract Res Clin Obstet Gynaecol 2003;17:75-92.

44. Deligeoroglou E, Athanasopoulos N, Tsimaris P, Dimopoulos KD, Vrachnis N, Creatsas G. Evaluation and management of adolescent amenorrhea. Ann N Y Acad Sci 2010;1205:23-32.

45. Practice bulletin no. 114: management of endometriosis. Obstet Gynecol 2010;116:223-36.

46. Grimes D, Jones LB, Lopez LM, Schulz KF. Oral contraceptives for functional ovarian cysts. Cochrane Database Syst Rev 2011;(9):CD006134.

47. American Academy of Pediatrics, Committee on Adolescence; American College of Obstetricians and Gynecologists, Committee on Adolescent Health Care. Menstruation in girls and adolescents: using the menstrual cycle as a vital sign. Pediatrics 2006; 118:2245-50.

48. Claessens EA, Cowell, CA. Acute adolescent menorrhagia. Am J Obstet Gyneco 1981;139:277-80.

49. Ahuja SP, Hertweck SP. Overview of bleeding disorders in adolescent females with menorrhagia. J Pediatr Adolesc Gynecol 2010;23(6 Suppl):S15-21.

50. US Department of health and Human Services, National Institutes of Health, National Heart Lung and Blood Institute. The diagnosis, evaluation, and management of von Willebrand disease. NIH publication no. 08-5832. December 2007. Available from: http://www.nhlbi.nih.gov/guidelines/vwd/vwd.pdf. Accessed on July 11, 2012.

51. Benjamins L. Practice guideline: evaluation and management of abnormal uterine bleeding in adolescents. J Pediatr Health Care 2009;23:189-93.

52. Deligeorogolou E, Tsimaris P, Deliveliotou A, Chrtistopoulos P. Menstrual disorders during adolescence. Pediatr Endocrinol Rev 2006;3(Suppl 1): 150-9.

53. Wilkinson J, Kadir R. Management of abnormal uterine bleeding in adolescents. J Pediatr Adolesc Gynecol 2010;23:S22-30.

54. Aslam N, Blunt S, Latthe P. Effectiveness and tolerability of levonorgestrel intrauterine system in adolescents. J Obstet Gynaecol 2010;30:489-91.

55. Hickey M, Balen A. Menstrual disorders in adolescence: investigation and management. Hum Reprod Update 2003;9:493-504.

56. Jones RK, Purcell A, Singh S, Finer LB. Adolescents' reports of parental knowledge of adolescents' use of sexual health services and their reactions to mandated parental notification for prescription contraception. JAMA 2005;293:340-8.

57. Klein DA, Hutchinson JW. Providing confidential care for adolescents. Am Fam Physician 2012;85: 556-60.

58. Guttmacher Institute. In brief: fact sheet. Facts on American teens' sexual and reproductive health. Available from: http://www.guttmacher.org/pubs/ FB-ATSRH.html. Accessed July 8, 2012. 